\title{
Prevalence of Diseases in Elderly Patients with Medication Related Problems
}

\author{
Abhishek Pradhan ${ }^{1}$, Fathimath Kamila Thasneem ${ }^{2}$, A R Shabaraya ${ }^{3}$ \\ ${ }^{1}$ Associate Professor, Department of Pharmacy Practice, \\ ${ }^{2}$ Student, Doctor of Pharmacy, Department of Pharmacy Practice, \\ ${ }^{3}$ Professor and Head, Department of Pharmacy Practice, Srinivas College of Pharmacy, Mangalore, \\ Karnataka- 574143
}

Corresponding Author: Fathimath Kamila Thasneem

\begin{abstract}
Introduction: The elderly population commonly known as geriatrics constitute nearly $21 \%$ of the world population. With the increasing age, the human body undergoes physiologic changes, leading to pharmacokinetic and pharmacodynamic alterations, hence making this sector of the patients more prone to medication related problems. Medication related problems are any unwanted events or circumstances that occur during the drug therapy which has the potential to interfere with the desired goals of health outcomes.
\end{abstract}

Methods: A community based observational study was conducted in different places of Dakshina Kannada district for a duration of 6 months by enrolment of 150 patients aged above 60 years of either sex diagnosed with any disease except for cancer and bed ridden patients. The data was collected with the help of patient interview forms and was analysed.

Results: Out of the 150 patients, 107 patients were identified with medication related problems. The total numbers of identified medication related problems were 196. From this study it was found that the medication related problems were more prevalent in cardiovascular disorders and endocrine disorders. As hypertension and diabetes mellitus are the most common diseases found among the elderly, the risk factors for developing medication related problems in such patients include the need of additional drug therapy or adequate monitoring of the clinical outcomes.

Conclusion: It was found that the geriatrics suffering from multiple co-morbidities undergoes multiple drug therapies thereby leading to medication related problems. Hence in order to ensure optimum care, a targeted approach is essential.

Key Words: Medication related problems, Geriatrics, Hepler-Strand classification

\section{INTRODUCTION}

The elderly population which comprise a major sect of the total human population are more prone to develop ailments due to the weakening of immune system with the increasing age. Hence they are more likely to have multiple drug prescriptions, which can eventually lead to medication related problems. According to the Pharmaceutical Care Network of Europe, medication-related problems (MRP) are defined as an event or circumstance involving drug therapy that truly or potentially interfere with desired health outcomes. ${ }^{[1]}$ There are eight categories of MRPs according to Hepler and Strand classification, which are tabulated below ${ }^{[2]}$ :

\begin{tabular}{|l|l|}
\hline $\begin{array}{l}\text { MEDICATION RELATED } \\
\text { PROBLEMS }\end{array}$ & DESCRIPTION \\
\hline Untreated Indication & $\begin{array}{l}\text { The patient has a medical indication that calls for drug therapy but is not receiving a drug } \\
\text { for the same }\end{array}$ \\
\hline Improper Drug Selection & The patient has an indication for a particular drug but is taking the wrong drug for it. \\
\hline Sub-therapeutic Dosage & The patient has a medical condition that is being treated with the correct drug but with too little of it. \\
\hline
\end{tabular}




\begin{tabular}{|l|l|}
\hline \multicolumn{2}{|c|}{ Table Continued... } \\
\hline Failure to Receive Drugs & $\begin{array}{l}\text { The patient has a condition by virtue of his or her not receiving a drug for pharmaceutical, } \\
\text { psychological, sociological or economic reasons. }\end{array}$ \\
\hline Over dosage & $\begin{array}{l}\text { The patient has a medical problem that is being treated with the correct drug but with too much of it } \\
\text { (may lead to toxicity). }\end{array}$ \\
\hline Adverse Drug Reactions & The patient has a medical problem due to an Adverse Drug Reaction or adverse effect. \\
\hline Drug Interactions & $\begin{array}{l}\text { The patient has a medical problem that caused by a drug-drug, drug-food or drug-laboratory } \\
\text { interaction/s. }\end{array}$ \\
\hline Drug Use Without Indication & The patient is taking a drug for no medically valid indication \\
\hline
\end{tabular}

With changes in the physiology of the organ systems in the elderly patients, they are at risk of developing chronic diseases. The most commonly occurring diseases in the elderly include cardiovascular diseases, osteoporosis, diabetes mellitus, osteoarthritis, and other multiple chronic conditions. ${ }^{[3]}$ Therefore, the development of these multiple ailments requires combination therapies. Hence, medication related problems can occur due to drug-drug interaction or a drug prescribed for a particular disease interacting and causing unwanted effects on an existing disease in a particular patient.

Several reasons exist for the relative lack of information about the medication related problems in the geriatrics. In contrast to in-patients, out-patients are responsible for both procuring and administering their own medications. Also, physicians do not have regular contact with outpatients and are hence less likely to come to be aware about their problems. ${ }^{[4]}$ Pharmacists interventions (medication review and a planning intervention at admission and at discharge) have a positive effect on prescribing in older adults, ensuring that they receive effective, safe, and efficient drug therapy. ${ }^{[5]}$ Hence, with proper intervention, a subsequent decrease in the medication related problems can be achieved. The study was carried out with an aim of identifying the more prevalent diseases in the elderly population with medication related problems in various parts of Dakshina Kannada district. The demographic features, clinical characterizations, comorbidities, and outcomes of the treatment were analysed in the study.

\section{MATERIALS AND METHODS}

A community based observational study was done to evaluate the medication related problems in elderly patients in the community setting of different regions of Dakshina Kannada district. The study was conducted among geriatric population above 60 years of age for the duration of 6 months from January 2021 to June 2021. The study was limited to a sample of 150 patients. The study protocol was approved by the Institutional Ethics Committee (IEC) of Srinivas Institute of Medical Science and Research Centre (SIMS \& RC), Mukka, Mangalore. The inclusion criteria of this study were patients of both sexes above 60 years of age, with any illness, on multiple medications and those who were willing to participate in the study. Patients less than 60 years of age, those diagnosed with cancer, who were bed-ridden and those not willing to participate in the study were excluded. Ethical committee approval was obtained before starting of this study. Patient interview form was designed as per need of the study. Community visits were done to homes of the patient and data were collected via patient interview and patient interview forms. The data collected included patient's demographic details, personal history, medical and medication history, current diagnosis, drug therapy details and any problems that were observed by the patient during the course of the treatment. All the data were kept confidential. Statistical analysis involved collecting and scrutinizing all data samples in a set of items. Further data samples were drawn and analyzed using Microsoft excel 2016.

\section{RESULTS}

A total of 150 elderly patients (aged above 60 years old) were enrolled in the 
study. Patient details along with their medical history were collected from each of them with the help of patient interview form and MRP risk assessment tool. Out of 150 patients, 82 were male and 68 were female. Among the 150 patients who participated in the study, 9 were alcoholic, 12 were smokers, 5 were both alcoholic and smokers and 3 of them were consuming tobacco products. 61 patients who participated in this study had more than 3 co-morbidities and 74 patients were prescribed with more than 5 drugs. The detailed demographic features of patients participated in this study is given in Table 1.

Table 1. Demographic features and clinical characterization of the patient

\begin{tabular}{|c|c|c|c|}
\hline VARIABLE & CATEGORY & FREQUENCY N=150 & PERCENTAGE \\
\hline \multirow{3}{*}{ AGE } & $60 \leq X>70$ & 76 & $51 \%$ \\
\hline & $70 \leq X>80$ & 56 & $37 \%$ \\
\hline & $\geq 80$ & 18 & $12 \%$ \\
\hline \multirow{2}{*}{ GENDER } & Male & 82 & $54 \%$ \\
\hline & Female & 68 & $46 \%$ \\
\hline \multirow{4}{*}{ SOCIAL HABITS } & Alcoholic & 9 & $6 \%$ \\
\hline & Smoking & 12 & $8 \%$ \\
\hline & Both Alcoholic and Smoking & 5 & $3.33 \%$ \\
\hline & Tobacco & 3 & $2 \%$ \\
\hline \multirow{2}{*}{ NUMBER OF DRUGS PRESCRIBED } & $1-4$ & 89 & $59.33 \%$ \\
\hline & $\geq 5$ & 61 & $40.66 \%$ \\
\hline \multirow{3}{*}{ NUMBER OF DISEASES } & Single illness & 30 & $20 \%$ \\
\hline & 2 co-morbidities & 32 & $21.33 \%$ \\
\hline & $\geq 3$ complications & 88 & $58.66 \%$ \\
\hline
\end{tabular}

Out of 150 patients who participated in this study, 107 patients were found to have MRPs. A total of 196 MRP's were identified from 107 patients which were classified according to Hepler-Strand Classification. Among 107 patients identified with MRP's, 56 male patients (68.29\%) and 51 female patients (75\%) had MRPs

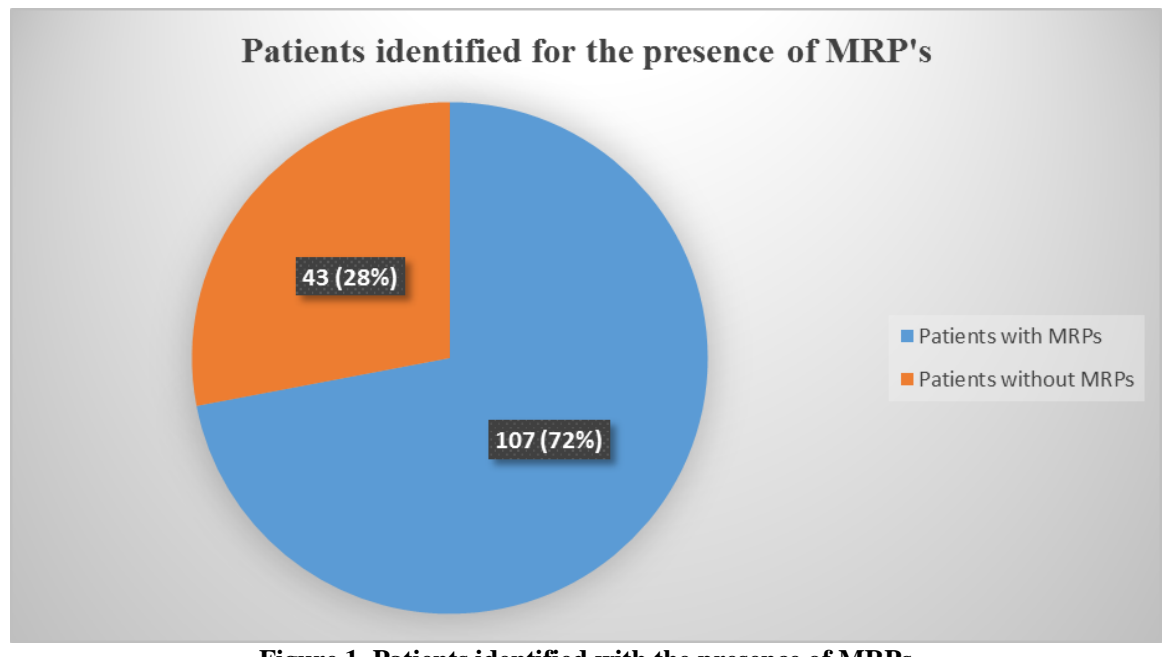

Figure 1. Patients identified with the presence of MRPs

\section{DISTRIBUTION OF MRPS AMONG STUDY SUBJECTS:}

Out of 150 patients, 107 patients were found to have MRPs. Among them, a total of 196 MRPs were identified. The identified MRPs were classified based on Hepler-Strand Classification as shown in Table 2.

Table 2. Distribution of MRPs among study population using Hepler-Strand classification-

\begin{tabular}{|c|c|c|c|}
\hline Types of MRPs & Description & $\begin{array}{l}\text { Frequency } \\
\mathrm{N}=196\end{array}$ & Percentage \\
\hline Untreated Indication & $\begin{array}{l}\text { The patient has a medical indication that calls for drug therapy but is not receiving a } \\
\text { drug for the same. }\end{array}$ & 13 & $6.63 \%$ \\
\hline $\begin{array}{l}\text { Improper Drug } \\
\text { Selection }\end{array}$ & The patient has an indication for a particular drug but is taking the wrong drug for it. & 26 & $13.26 \%$ \\
\hline $\begin{array}{l}\text { Sub therapeutic } \\
\text { Dosage }\end{array}$ & $\begin{array}{l}\text { The patient has a medical condition that is being treated with the correct drug but } \\
\text { with too little of it. }\end{array}$ & 13 & $6.63 \%$ \\
\hline
\end{tabular}


Abhishek Pradhan et.al. Prevalence of diseases in elderly patients with medication related problems.

\begin{tabular}{|l|l|l|l|}
\hline \multicolumn{3}{|c|}{ Table 2. Continued... } & $10.71 \%$ \\
\hline $\begin{array}{l}\text { Failure to Receive } \\
\text { Drugs }\end{array}$ & $\begin{array}{l}\text { The patient has a condition by virtue of his or her not receiving a drug for } \\
\text { pharmaceutical, psychological, sociological or economic reasons. }\end{array}$ & 21 & $7.14 \%$ \\
\hline Over dosage & $\begin{array}{l}\text { The patient has a medical problem that is being treated with the correct drug but with } \\
\text { too much of it (may lead to toxicity). }\end{array}$ & 14 & $47.49 \%$ \\
\hline $\begin{array}{l}\text { Adverse Drug } \\
\text { Reactions }\end{array}$ & $\begin{array}{l}\text { The patient has a medical problem due to an Adverse Drug Reaction or adverse } \\
\text { effect. }\end{array}$ & 93 & $7.14 \%$ \\
\hline Drug Interactions & $\begin{array}{l}\text { The patient has a medical problem that caused by a drug-drug, drug-food or drug- } \\
\text { laboratory interaction. }\end{array}$ & 14 & $1.02 \%$ \\
\hline $\begin{array}{l}\text { Drug Use Without } \\
\text { Indication }\end{array}$ & The patient is taking a drug for no medically valid indication. & 2 & \\
\hline
\end{tabular}

\section{DISTRIBUTION OF IDENTIFIED MRP's ACROSS DISEASES}

Table 3. Distribution of identified MRP's across various diseases.

\begin{tabular}{|c|c|c|}
\hline Types of MRPs & Diagnosed diseases & Number of patients \\
\hline \multirow{3}{*}{ Untreated Indication } & Anemia & 8 \\
\hline & Gastro Esophageal Reflux Disease & 4 \\
\hline & Skin infections & 1 \\
\hline \multirow{9}{*}{ Improper Drug Selection } & Hypertension & 5 \\
\hline & Diabetes Mellitus & 8 \\
\hline & Portal hypertension & 2 \\
\hline & Migraine attacks & 1 \\
\hline & Peptic Ulcer Disease (PUD) & 3 \\
\hline & Urinary Tract Infection & 2 \\
\hline & Stroke & 2 \\
\hline & Parkinson's Disease & 2 \\
\hline & Alzheimer's Disease & 1 \\
\hline \multirow{6}{*}{ Sub therapeutic Dosage } & COPD & 3 \\
\hline & Hypertension & 3 \\
\hline & Chronic Liver Disease & 2 \\
\hline & Coronary Artery Disease & 2 \\
\hline & Seizure & 1 \\
\hline & Diabetes Mellitus & 2 \\
\hline \multirow{7}{*}{ Failure to Receive Drugs } & Diabetes Mellitus & 5 \\
\hline & Hypertension & 8 \\
\hline & Stroke & 1 \\
\hline & Alzheimer's Disease & 1 \\
\hline & PUD & 2 \\
\hline & Inflammatory Bowel Disease & 1 \\
\hline & Asthma & 3 \\
\hline \multirow{6}{*}{ Over dosage } & Arrythmia & 2 \\
\hline & Asthma & 2 \\
\hline & COPD & 1 \\
\hline & Chronic Kidney Disease & 4 \\
\hline & Thyroid & 4 \\
\hline & Hepatitis & 1 \\
\hline \multirow{17}{*}{ Adverse Drug Reactions } & Hypertension & 11 \\
\hline & Diabetes Mellitus & 8 \\
\hline & Coronary Artery Disease & 6 \\
\hline & Parkinson's Disease & 2 \\
\hline & Stroke & 4 \\
\hline & Asthma & 7 \\
\hline & COPD & 5 \\
\hline & Chronic Kidney Disease & 15 \\
\hline & Hepatitis & 4 \\
\hline & Chronic Liver Disease & 3 \\
\hline & Arrythmia & 5 \\
\hline & Seizure & 4 \\
\hline & PUD & 3 \\
\hline & Inflammatory Bowel Disease & 3 \\
\hline & Gastro Esophageal Reflux Disease & 5 \\
\hline & Thyroid & 4 \\
\hline & Urinary Tract Infection & 4 \\
\hline \multirow{6}{*}{ Drug Interactions } & Hypertension & 3 \\
\hline & Diabetes Mellitus & 3 \\
\hline & Coronary Artery Disease & 2 \\
\hline & Urinary Tract Infection & 3 \\
\hline & COPD & 1 \\
\hline & Chronic Kidney Disease & 2 \\
\hline \multirow{2}{*}{ Drug Use Without Indication } & Hypertension & 1 \\
\hline & Anemia & 1 \\
\hline
\end{tabular}


In the study, it was found that MRPs were more commonly seen in cardiovascular disorders and endocrine disorders. The distribution of identified MRPs across various diseases is given in Table 3.

\section{DISCUSSION}

Medication related problems are becoming a major public health concern. Elderly patients are particularly highly vulnerable to MRP's caused by multiple factors such as poly-pharmacy, and inappropriate prescribing. ${ }^{[6]}$ Hence, identification and prevention of MRP's in this population is very crucial. So, an observational study was conducted to identify and assess various medication related problems found in the community setting of our study by using Hepler-Strand classification.

In the present study, 150 elderly patients of either sex aged above 60, diagnosed with one or more diseases have participated. A total of 107 patients were found to have MRPs. This study also showed that medication related problems were found to be increasing with the increasing number of diseases. This is mainly because as the complications in the patients increases, the need to treat the comorbidities also increases eventually leading to prescribing more drugs. Hence, poly-pharmacy increases the risk of drug interactions and other MRP's. According to a study by M Saljoughian et al, the presence of MRPs increased with the number of drugs used. Researches have shown that patients taking 5-9 medications have a 50\% chance of an adverse drug reaction, increasing to $100 \%$ when they are taking 20 or more medications. ${ }^{[7]}$

As a patient ages, co-morbidities increase as well as increase the risk of medication related problems and the ability to eliminate medications from the body becomes less efficient with aging due to reductions in kidney and liver function. So, the selection of medication, dosing schedules, and combined drug regimens, as well as appropriate follow-up and management of medication treatment, should always be age-specific and highly individualized among older adults ${ }^{[8]}$

The diseases identified with MRP's in this study were categorized as cardiovascular diseases, disorders of the central nervous system, endocrine disorders, respiratory disorders, kidney disorders, blood disorders, hepatic disorders and others. The diseases of the cardiovascular system and endocrine system were having the greatest number of MRP's. This finding was also supported by a similar study conducted by A Al Hamid, M Ghaleb et al. [9] The reason for this might be due to the elderly population perceiving the most common ailments such as hypertension and diabetes mellitus as age related and hereditary and having misconceptions and not adhering to the prescribed therapy. The main risk factors for developing medication related problems in cardio-vascular disease patients, were the need of additional drug therapy and lack of therapeutic monitoring. ${ }^{[10,11]}$ Not only this, from this study it was also found that, drugs such as calcium channel blockers, beta blockers, ARB's, statins, diuretics, antihyperlipidaemics, oral hypoglycaemic agents, antibiotics, bronchodilators, NSAIDS, anticoagulants, thyroid hormones, gastro protectants, anti-epileptic agents and dopamine agonists etc. were more frequently involved in causing medication related problems.

Therefore, the present study provides an extensive data on the diseases which are more prevalent with MRP's encountered by the elderly population in the community settings of Dakshina Kannada. As confirmed by the results of the present study, the number of MRP's in elderly patients can be minimized by using comprehensive tools to identify them. An important task for community pharmacists is therefore to identify, resolve and prevent the occurrence of MRP in this group of patients for a better health outcome. This study was conducted for a short duration of 
time. Also it was difficult to approach some of the elderly patients directly due to COVID-19 pandemic. However, our findings could set the stage for future studies to address the causal relation between elderly patients and diseases most commonly causing medication related problems in them.

\section{CONCLUSION}

The consumption of medications in any disease condition is unavoidable. But unnecessary use of medications in patients especially in the elderly population who will be having multiple co-morbidities can be a reason for compromising their health. Current prescribing practices of geriatrics showed inappropriate medications, making these populations more vulnerable to adverse drug reactions and drug interactions. Hence, judicious prescription of drugs and careful and frequent monitoring of drug therapy are necessary to reduce the risk of medication related problems.

\section{Acknowledgement: None}

\section{Conflict of Interest: None}

\section{Source of Funding: None}

\section{REFERENCES}

1. Starner CI, Gray SL, et al. Pharmacotherapy a Pathophysiologic Approach. 7th ed. New York: McGraw-Hill Medical; 2008. pp. 5766.

2. Hepler CD, Strand LM. Opportunities and responsibilities in pharmaceutical care. American journal of hospital pharmacy. 1990; 47(3): 533-543.

3. Jaul E, Barron J. Age-related diseases and clinical and public health implications for the 85 years old and over population. Frontiers in public health. 2017; 5:335.
4. O'Neil AC, Petersen LA, Cook EF,et al. Physician reporting compared with medicalrecord review to identify adverse medical events. Annals of internal medicine. 1993; 119(5): 370-376.

5. Cortejoso L, Dietz RA, Hofmann G,et al . Impact of pharmacist interventions in older patients: a prospective study in a tertiary hospital in Germany. Clinical interventions in aging. 2016; 11: 1343.

6. Moral EG, Suarez-Varela MM, Esteban $\mathrm{JH}$,et al. Inappropriate multiple medication and prescribing of drugs in immobile elderly patients living in the community. Atencion primaria. 2006; 38(9): 476.

7. Saljoughian M. Polypharmacy and drug adherence in elderly patients. US Pharm. 2019; 44(7): 33-36.

8. Fialová D, Kummer I, Držaić M. Contemporary Perspectives on Ageism. 2018; 213-240

9. Al Hamid A, Ghaleb M, Aljadhey H,et al. A systematic review of qualitative research on the contributory factors leading to medicinerelated problems from the perspectives of adult patients with cardiovascular diseases and diabetes mellitus. BMJ open. 2014; 4(9):e005992.

10. Abdela OA, Bhagavathula AS, Getachew $\mathrm{H}$,et al. Risk factors for developing drugrelated problems in patients with cardiovascular diseases attending Gondar University Hospital, Ethiopia. Journal of pharmacy \& bioallied sciences. 2016; 8(4): 289.

11. Shwetha N, Pradhan A, Shabaraya AR et.al. New risk factors for developing drug related problems in patients with cardiovascular diseases. International Journal of Research and Review. 2021; 8(3):403-409.

How to cite this article: Pradhan A, Thasneem FK, Shabaraya AR. Prevalence of diseases in elderly patients with medication related problems. International Journal of Research and Review. 2021; 8(9): 228-233. DOI: https:// doi.org/10.52403/ijrr.20210931 